\title{
Why Open Innovation is Easier Said Than Done: An Organizational Identity Perspective
}

\begin{abstract}
Maral Mahdad
maral.mahdad@wur.nl | Business Management \& Organisation Group, Wageningen University \& Research, Hollandseweg 1, 6706 KN Wageningen, The Netherlands.

Chiara E. De Marco

c.demarco@ciaotech.com | CiaoTech s.r.l. - PNO Group, Via Giovanni Pacini 11, Milan 20131, Italy

Andrea Piccaluga

andrea.piccaluga@santanapisa.it | Institute of Management, Scuola Superiore Sant'Anna, Piazza Martiri della Libertà 24, Pisa 56124, Italy

Alberto Di Minin

a.diminin@santanapisa.it | Institute of Management, Scuola Superiore Sant'Anna, Piazza Martiri della Libertà 24, Pisa 56124, Italy

Abstract. In this article, we explore and interpret organizational identity transformation associated with the open innovation strategy of the largest telecommunication company in Italy, Telecom Italia (TIM). When TIM established eight joint laboratories within five major Italian universities to benefit from opening its business model, it transferred some R\&D employees to the new laboratories to work with the university scientists. This organizational transformation imposed challenging conditions for $R \& D$ employees engaged in the open innovation activities of the firm. We conducted an interpretative phenomenological analysis (IPA) to answer the question of "how do R\&D employees experience the implementation of an open innovation strategy from an organizational identity perspective?" Our analysis is based on the interpretation of the lived experiences of 14 employees. Studying the phenomenon of open innovation implementation using the lens of organizational identity suggests the following: (1) The process of open innovation through mobility of skilled $\mathrm{R} \& \mathrm{D}$ employees triggers organizational identity ambiguity and change, (2) Organizational identity ambiguity phase in the process of open innovation can be shortened by the support of parent company and managerial skills highlighting sensemaking mechanisms, (3) Constructing a shared organizational identity with university members involved in this process is an undeniable element of OI success. We contribute to the literature by establishing linkages among organizational identity and open innovation and building on recent works on the role of individuals within open innovation ecosystems. Our qualitative analysis draws on a conceptual framework for open innovation and organizational identity transformation.
\end{abstract}

Keywords. Open Innovation; Organizational Identity; University-Industry Collaboration; Joint Laboratories.

Cite paper as: Mahdad, M., De Marco, C., Piccaluga, A., Di Minin, A., (2020). Why Open Innovation is Easier Said Than Done: An Organizational Identity Perspective, Journal of Innovation Management, www.open-jim.org, $8(2), 47-67$.

ISSN 2183-0606

http://www.open-jim.org

http://creativecommons.org/licenses/by/3.0 


\section{Introduction}

In this article, we conduct an interpretative phenomenological analysis (IPA) to answer the question of "how do R\&D employees experience the implementation of an open innovation strategy from an organizational identity perspective?" In order to address this question, we explore and interpret the phenomenon of open innovation strategy implemented through the mobility of high skilled employees, applying the theoretical lens of organizational identity. Our study sheds light on the underexplored conditions that organizational identity transformations generate in the process of an organizational change, related to a specific mode of implementing the open innovation strategy, i.e. the collaboration between university and industry.

Chesbrough and Bogers (2014) provided the most recent definition of open innovation describing it as knowledge flows across organizational boundaries using mechanisms in line with the organization's business model. Open innovation scholars have studied this paradigm across different level of analysis, but the individual level received limited attention (e.g., Salter et al. 2015). Bogers et al. (2016) called for more research on how individuals within an organization cope with the new challenges of open innovation strategies. In their research, there is a specific invitation for organizational behavior and identity scholars, to address the question of how R\&D employees experience change when they start involving more in the activities outside the organizational boundaries.

In the last decade, innovation studies gave significant attention to the sources of knowledge external to the firm. Chesbrough (2006) noted that firms employ 'open innovation' strategies to tap into external R\&D, share uncertainties and risks and leveraging on a distributed interorganizational network. Following this trend, universities became an interesting source of external knowledge for companies that look for opening up strategies. Firms usually choose to build up collaborative networks with universities, especially when the aim is to acquire tacit and uncodified knowledge (Yusuf, 2008). However, Perkmann \& Walsh (2007) noted that according to the concept of open, in networked or interactive innovation, the actual ties between university and industry play a stronger role rather than the symbolic links in generating innovation. According to him, in the 'open innovation' context, the links with high relational engagements are beneficial for partners, as they enable building and maintenance of inter-organizational relationships over time. An example of these links is the mobility of staff/researchers as, for example, the cases of academics deciding to manage their own research spin-off, or temporary or industrial scientists moving to laboratories where they can closely work with university scientists. In these cases, the organization goes through a process of subtractive change (e.g. spin-offs, de-merges, elimination of units, against the additive changes related to, e.g., merges, new unit creation, assimilation). The subtractive change questions members' understanding of organizational identity (Corley and Gioia, 2004). Indeed, the establishment of university-industry joint laboratories - outside of the firm's boundaries and within university's ones - can configure as a subtractive change to the firm. In this context, companies' employees that move to work within the laboratories become outsiders to their own organization and go through an identity change over the process of implementation of the open innovation strategy. Corley and Gioia (2004) pointed out the lack of understanding around identity change dynamics in this context.

While open innovation is indeed well researched, the role of individuals and human resources 
within a collaborative innovation process - especially in the form of separate research entities is still not fully understood. Feller (2005) and Nelson (2004) raised the necessity of exploring what institutional and organizational conditions can and should be reconfigured to make universityindustry collaboration work more efficiently, while West et al. (2014) emphasized the role of human resources in open innovation processes as a specific research gap. Furthermore, the research on open innovation has not clearly investigated changes and challenges that result from adopting open innovation, particularly at the individual level of analysis. The research has been focusing more on the organizational level of exploration both for open innovation and organizational identity, neglecting the analysis at the individual level (Reissner, 2019). Therefore, the challenges that managers of collaborative processes might face need further investigations. Organizational identity of $R \& D$ employees might, indeed, be affected by the implementation of an open innovation strategy by the parent firm, especially when stable employees turn to be mobile and enter new organizational setting.

In this article we address these underexplored issues by focusing on employees who went through this transformation and joined cooperative research centers between university and industry. Our interpretative phenomenological analysis (IPA) sheds light on the literature on open innovation and organizational identity theories. We base our analysis on interpreting lived experiences of 14 employees.

Our study contributes to the literature in three ways. First, by establishing linkages among organizational identity and open innovation, we shed light on how elements of the organizational identity change are triggered in the implementation of an open innovation strategy, particularly through the mobility of skilled R\&D employees (Chesbrough, 2006). Second, building on recent works on the role of individuals within open innovation ecosystem (Bogers et al., 2016), we emphasize the importance of human resources in open innovation research. Finally, our paper adds to organizational identity theory not only by bringing open innovation into the discourse and conceptualizing it, but also employing IPA in addressing organizational identity change (Gioia et al., 2013). Our qualitative analysis draws on a conceptual framework for open innovation and organizational identity transformation. The following sections include a brief review of organizational identity and the process of change/transformation. We continue by introducing the methodology applied, followed by our results and concluding remarks.

\section{Literature background}

\subsection{The changes related to open innovation strategy implementation}

Firms' open innovation implementation covers a wide range of practices, such as in-/out-licensing (van de Vrande et al., 2009), involvement of different stakeholders in the open innovation ecosystem (van de Vrande et al., 2009), participation in public technology transfer programs (Dodgson et al., 2006). Open innovation practices also include research contracts and ventures with universities (Perkmann and Walsh, 2007). Regardless of the type of activity chosen, organizations still face a variety of challenges in practicing open innovation. Scholars highlighted two categories of challenges: internal and external, according to whether they arise within or beyond organi- 
zational boundaries (De Marco, 2017). While the external challenges of open innovation result more impactful for SMEs (De Marco et al. 2020), the internal ones appear more severe for large organizations, as they are related to the organizational and cultural changes needed to favor the successful implementation of the open innovation strategy.

Addressing these challenges to deploy different practices within the open innovation paradigm requires not only knowledge and resources, but also expertise. According to Chesbrough (2006), the increasing attention toward opening $R \& D$ procedures requires new organizational choices for R\&D. In this paradigm, universities have been treated as important external actors in facilitating access to new scientific knowledge (Klevorick et al., 1995; Belderbos et al., 2004). Collaboration with universities is perceived as a productive mean for partnerships at the technology/knowledge development level (Chesbrough, 2003; Harwing, 2004; Blau, 2007). Establishing joint laboratories with universities has not been excluded from this trend as shown, for example, in the case of Deutsche Telekom creating an open innovation ecosystem with universities by establishing T-Labs (Rohrebeck et al. 2009). Providing a separate organizational structure for academics and R\&D personnel allows overcoming many barriers associated with university-industry collaborations (Rohrbeck and Arnold, 2006; Mahdad et al., 2018). Indeed, even the practice of establishing separate organizational structures for open university/industry collaboration is not free from challenges. The organizational and cultural (internal) challenges of such structure can emerge when industry collaborates with academia in ad hoc created laboratories and scholars showed how applying structural properties of adaptive capacity can trigger positive effects and help in handling these challenges (Mahdad et al, 2019)

\subsection{The mobility of high-skill workers}

Literature recognized the role of labor mobility, particularly of high-skilled workers, as the most effective mean enabling the transfer of knowledge and skills (Arrow, 1962; Gilson, 1999). Since knowledge is embedded in individuals, their movements across firms and organizations generate involuntary spillovers of tacit knowledge transfer. A strong body of literature focused on the importance of labor mobility and its positive impact on regional culture, including on nonhierarchal business culture and socio/cultural learning features (Saxenian, 1994; Florida, 2000). Scholars also highlighted the importance of factors and attitudes that can facilitate mobility impacts, such as the willingness to experiment and take risks, informality of work styles, and high occupational mobility (Saxenian, 1994). Despite the definition of open innovation is based on the flows of knowledge and, as mentioned, workers mobility is a major mean to make knowledge flow, not many studies focused on the impact of workers' mobility within open innovation. However, in the specific practice of open innovation in which industry collaborates with academia, scholars identified the transfer of human resources, i.e. movements of the staff between the two types of organizations, as a learning mechanism and knowledge transfer mean (Perkmann and Walsh 2007; De Fuentes and Dutrénit, 2012). Literature showed that the interorganizational mobility of employees implies the dissemination of cognitive resources derived from the organization of origin, even influencing innovation capabilities (Herstad et al., 2015).

While the phenomenon of knowledge transfer and collaboration between university and industry have been widely explored at the organizational level, literature still lacks clear understanding 
of the dynamics at the individual level (Bogers et al. 2016, Perkmann et al. 2013). Perkmann et al. (2013) argue that a good understanding of the individual behavior in the collaboration between academia and industry would benefit the overall organizational performance. Moreover, shedding light on how individuals adapt to the rules of their work contexts and how they react to different institutional logics, would contribute to the understanding of the open innovation phenomenon in its university-industry collaboration form.

\subsection{Open Innovation and organizational identity}

According to Petroni et al. (2012), open innovation influences R\&D personnel for their role in inter-organizational innovation activities. When open innovation comes into the debate, the dynamics of organizational and individual collaboration merge and need to be managed with a human-centric approach, rather than an organizational-centered one, as individuals deal with the uncertainty of the 'give-and-take' of the collaboration that generates innovation (Salampasis and Mention, 2017; Webb 2017). This 'give-and-take' is the source of innovation as it comes from the above-mentioned knowledge flows. Nonetheless, grasping external knowledge is very different from generating internal innovation. When we talk about open innovation adoption and its process, the attention should also move toward actors within this paradigm. R\&D employees are directly involved in the process of innovation, weather it is closed or open. Changing the organizational structure might have various influences on the organization itself and its members, including a change in organizational identity (Gioia and Thomas, 1996). Organizational identity is considered crucial for organization development since it affects actions, interpretation, and decision making of the members and management. Indeed, in open innovation, employees coming from different organizations keep representing their parent one, but still identify with the new organization established for the collaboration, incurring in identity shifts that might affect joint innovation activities (Webb 2017). For these reasons, scholars suggested the combination of managerial actions that can drive the dynamics related to the 'dual allegiance' of R\&D employees involved in the exchange of knowledge during collaborative projects: a good governance of the balance between disclosure and protection of knowledge would allow success of collaboration (Husted and Michailova, 2010).

The concept of organizational identity was initially introduced by Albert and Whetten (1985) as a set of features that should be central, enduring and distinctive. Hatch and Schultz (2002), complemented this concept as a 'reflective dialogue between the organization and social context'. Whetten (2006) referred to the features of organizational identity that conceptualize selfreferencing and help members to construct a collective sense of self that satisfies organizational and individual needs for continuity, coherence and distinctiveness.

Albert and Whetten (1985) proposed three definitional elements of organizational identity:

- What is taken by organization members as being central within an organization and the organization's work, such as beliefs and norms, that cannot be changed without redefining the organization itself.

- How organization members distinct their organization from other similar ones, e.g. from competitors (Ravasi \& Phillips, 2011). 
- How organization members endure or link the past, present and presumably future of the organization activities to each other.

Other scholars evolved and redefined the definition of organizational identity after Albert and Whetten's work. Gioia (1998) defined organizational identity as a 'shared answer to the question of "who we are as an organization?"; later, Navis \& Glynn (2010) built upon this definition by including "what do we do?". Many scholars noted that organizational identity refers to the collective level where members define themselves relating to the organization (Ashforth and Mael, 1989; Corley and Gioia, 2004; Corley et al., 2006). In contrast, Polos et al. (2002), defined organizational identity as a concept of the organization held by outsiders rather than its members. Scholars have been investigating the organizational identity theory within different context. The static perspective of organizational identity has been recently changed to a more fluid one, considering a process view of organizational identity (Hatch and Schultz, 2002). From another perspective, Scott \& Lane (2000) believe that organizational identity is neither static nor fluid, but it is rather 'sticky', meaning that organization members tend to preserve the old identity and resist the change.

Although there have been complementary definitions of organizational identity in the field of organization studies, Albert and Whetten's definition (1985) seems to be the backbone of this literature. Therefore, we also build our research on their 'three pillars' definition of organizational identity. However, we use this definition more in a dynamic than a static setting, to see how the main features of identity might change during an open innovation process.

The important role of 'enduring' features of organizational identity comes into the debate when a change or transformation occurs to the members of an organization. The debate over the 'continuity' element of organizational identity can rely on a strong body of research confirming that identity can change over time (Corley and Gioia, 2004; Dutton and Dukerich, 1991; Fiol, 2002). Organizational identity received significant attention in studies on different transformational phenomena, particularly acquisition (Melewar and Harrold, 2000; Reade, 2001; Vaara et al. 2003; Ullrich et al. 2005; Bartels et al. 2006; Van Dick et al. 2006), and post-acquisition integration (Van Knippenberg and Van Leeuwen, 2001). Corley and Gioia (2004) highlighted temporal identity discrepancy and change in social referent as triggers of organizational identity transformation, while the importance of managing image and identity during a radical change has been studied by Fiol (2002). According to Vieru and Rivard (2012), challenges of organizational identity change appear not only with members' attempts to answer the question "Who are we?", but also with the question of "Who do others think we are?".

In accordance with this, an open innovation practice can be very challenging for R\&D employees who join a new organization with new institutional settings. Scholars highlighted how organizational identity elements can generate employees' resistance to technological changes and innovation perceived as going against their organization identity (Tripsas 2009). Nonetheless, supporting the dynamic view of identity, Lifshitz-Assaf (2018) recently connected the literature on open innovation to the one on organization identity, showing how professionals' identity is crucial to avoid resistance to change and innovation.

Three decades of research on organizational identity topics built a rich body of literature; even though, scholars still call for more research on the relevance of organizational identity for the 
inter-organizational phenomenon, i.e. open innovation (Randawa et al. 2016; Bogers et al., 2017), and the conceptualization of the field, e.g. learning, strategy, innovation, etc. (Gioia et al., 2013). Trying to answer these calls, our research's goal is to address the question of 'how do R\&D employees experience the implementation of an open innovation strategy from an organizational identity perspective?'. In doing so, we aim at enriching the literature on organizational identity and open innovation by providing empirical evidence of the relation between open innovation practices and organizational identity change. In addition, this research contributes to the recent literature of open innovation and the importance of $R \& D$ employees as a unit of analysis. We use the term organizational identity transformation when R\&D employees change their organization as a part of the parent company's decision of opening its business model.

\section{Method}

We chose a qualitative research design because it gives importance to interpretation, descriptions, characteristics and meaning (Kvale, 1996).

Denzin \& Lincoln (2004) established the relevance of qualitative research in the field of human behavior. In addition, we chose qualitative approach to understand the true value of the employees' behaviors beyond numbers and measure. Exploring the phenomenon based on participants' experiences was the main aim of this research. Willig (2001) noted that qualitative research is able to connect the researcher to the experience of the individuals' context. Qualitative methodologies in organization studies include different methods of interpreting and exploring participants' experiences.

For this research, we chose interpretative phenomenological analysis (IPA) over other qualitative methods because of our focus on the phenomenon of experiencing organizational change in the process of open innovation implementation. We aim to enrich the theory rather than generating new ones. According to Gill (2014), phenomenological methodologies enable researchers to adopts a more dynamic and process view of organizational identity in their research contexts. Gill claims that the supporters of this perspective (e.g. Corley et al., 2006) believe that organizational identity is truly phenomenological, which means that it is something experienced as a phenomenon by organizational members. In our study, because of its focus on how employees interpret and make sense of a particular experience, namely change, Smith's IPA (1996) offers a suitable methodology to address our understanding of organizational identity in the context of open innovation.

IPA's distinctive element is its high emphasis on interpretative and idiographic account rather than seeking subordinate themes that emerge through data codification (Gill, 2015). The ideal situation is to have rich data from few informants rather than having enough numbers of participants. IPA is an established methodology mostly in the field of psychology (Smith, 1996). Using semi-structured interviews with a small set of participants, normally from two to ten in IPA, gives researchers a taste of participants' experiences through an interpretative analysis. IPA methodology does not test hypotheses and is neither inductive or abductive. It is a pure interpretation of researchers aiming to understand the participants' lived experiences without imposing the constraints of prior theory. There is a lack in using any phenomenological methodologies within the 
scope of organizational identity studies even though scholars refer to organizational identity as phenomenological and highly dependent on experiences of organizational members (Gill, 2014). Therefore, we chose IPA to understand employees' experience when the parent company decides to open its business model and how this organizational change influence how participant make sense of their current world and experience. Moreover, in our case, IPA provides an explanatory perspective that can complement other approaches in enriching existing theory.

\subsection{The case of Telecom Italia}

Telecom Italia (TIM) changed its innovation model to agile model of innovation, which enhances co-creation and co-development. Since 2012, TIM opened up eight joint laboratories within five major Italian universities as a strategy to take a step forward in the adoption of the open innovation paradigm. The Joint Open Laboratories (JOLs) are research and innovation laboratories set up within university centers, as a result of partnerships and agreements between TIM and the universities in specific fields of scientific and technological domains. The establishment of the JOLs aimed at overcoming barriers of collaboration between university and industry in practicing open innovation by transferring and mobilizing skilled $R \& D$ employees to the new organization structures within universities.

\subsection{Participants}

Participants of the study were initially R\&D employees who moved from TIM or any branch of TIM to work in the new organizational setting of the JOLs. Eight employees moved voluntarily (transferred employees), because of their field of interest or personal motivations. Preliminary results showed that the six employees directly employed (newly hired employees) by the JOLs could also provide valuable insights. Therefore, we included a total of 14 employees from both groups in our study.

\subsection{Data collection}

We performed semi-structured interviews that lasted between 45 minutes to 90 minutes. The topics of discussion with participants concerned the organization of the parent company and organization of JOLs; how do they perceive themselves as employees; what TIM and JOLs expects from them; how do they experience moving from TIM to JOL. These questions were open-ended and allowed participants to talk about the topic in a detailed way. The researcher remained for 2-5 days within each laboratory to further observe and collect data. This allowed researchers to enter participants lived experiences.

\subsection{Data analysis}

The interviews were recorded and then transcribed. We used Smith et al. (2009) method to initiate the data analysis process including thematic coding on single interview and identified 
table themes for the group followed by interpretation of meanings of participants' experiences. Nvivo software was used as a qualitative data management tool. We stored extracted themes in Nvivo and this allowed to manage and interpret qualitative data by eliminating the need for many of the manual tasks traditionally associated with qualitative analysis (Sorensen, 2008). As we mentioned, the aim of the IPA is to interpret rich data rather than coming up with a pattern in the themes and sub-themes.

\section{Findings and discussion}

The explanatory case design allows us to investigate the distinct phenomena of identity transformation when a company opens up by establishing research centers in collaboration with universities outside of the firm and undertakes labor mobility strategies to bring the knowledge generated from the labs inside the company. The initial basis of our findings emerged from the question 'how do you find yourself within the organization?'. The analysis is driven from the variety of subthemes emerged and can be categorized in three stages or three main themes.

We divide the process through which employees went into two stages: 1) shift from company's core identity to ambiguous identity and 2) construction of an open identity. We explain how TIM employees sustain the identity transformation and what are the mechanisms involved in different stages of identity transformation. The existence of core organizational identity (the identity that is related to parent company and employees who transferred from the parent company to the new venture) provided a firm baseline to start from.

\subsection{First stage: From company's core identity to identity ambiguity}

We started to explore individual's experience by interpreting their responses on how their core organizational identity changed (if changed) when entering to a new institutional context. TIM's paradigm shift - moving from closed to agile business model by implementing radical open innovation practice - enforced an institutional change on employees who had to move to a new venture, the JOLs established within the universities.

Central characteristic of the main company's organizational identity faces discontinuities. Employees that moved into JOLs had to maintain the organizational identity but being ready to also include some elements of the newly formed research center's identity. Features, beliefs and norms had to be transformed to the new ones due to the redefinition of a new institutional context. Based on our interpretation, we observe that in some cases the research center's director helped maintaining the central identity attributes of the organization. This was more visible in the JOLs that, in terms of physical distance, were closer to TIM.

"We have a contract with university but our rules and structure are still of the company, (even though) I have the feeling that in the company there is no idea of what is this innovation and who we are." (Transferred employee)

The theoretical explanation of the mechanisms that maintain centrality in the core organizational identity can be found in the "sensemaking" literature (Fiol, 1991, Corley and Gioia 2004). 
The centrality and firmness of norms and beliefs within an organization positively influence perceived organizational identity by employees and thus their performance. In our case, TIM risked the centrality of its organizational identity by creating a new institutional setting for those employees who were transferred from the central site to new locations. Different identities were formed when this institutional change occurred as a result of radically practicing open innovation and conflicting visions and beliefs emerged among employees who associated themselves to the new research center as central to their identity, with the ones who maintained the parent identity. Indeed, the few employees employed directly by the research centers tended to associate themselves with the parent company as their identity is stronger and well-structured.

The role of directors in creating a balanced view in the current ambiguous identity situation, was undeniable. Directors first reinforced central beliefs and, then, helped employees sustaining the vision shift. The important role of leaders becomes evident here. When asked whether they considered themselves as a member of the JOL or TIM, research centers' directors responded: 'Of course TIM'.

"We are using the open innovation paradigm but we are new to this approach, everyone in the lab is aware of this approach but I am not sure if other departments of the company know about open innovation and that we are involved in this approach. We are TIM and we are not any kind of spin-off or an independent company."(JOL director/transferred)

Identity endurance was challenged in the process of moving from stable identity to a more flexible one. In our interviews, employees projected an inconsistent identity especially in the initial phases of institutional transformation. The main unclear situation was when employees had doubt on whether to maintain the core identity of TIM or build a new identity shared with university representatives.

"What we do as company is really state of the art and innovative. We give a very good image of TIM to the outside of the company and I think we need to better understand the environment and where we belong to." (Transferred employee)

Identity alignment practices were found to be beneficial in overcoming ambiguous situation. The phase of ambiguity in identity endurance was facilitated by reinforcement practices such as directors' strategic actions for the vision alignment, and practices that were deployed by the company in order to involve mobile employees in the internal activities. Our interviewees argued that this was difficult to implement because employees should maintain consistent images of their existing identity over time, but the meanings linked to these images would change in order to suit new institutional settings (i.e. being in a joint laboratory). However, this has been a puzzled discussion in the field of organizational identity and change as well, especially when organizational identity issues arise during the implementation of structural changes in the organization.

To deal with distinctiveness feature of organizational identity, lab directors faced a twofold problem related to, on one side, the employees who had to make a distinction between the parent firm and other similar companies and, on the other side, the ones that had to be able to differentiate their research center from similar ones. In our dataset, managers who refined the identity overcame the identity ambiguity phase faster than the ones who solely enriched 
the core TIM identity. Constant re-elaboration of identity attributes aimed at fitting changing organization's goals and missions helped employees redefining identity distinctiveness.

The first phase of the organizational identity change process has been discussed similarly in the literature. Some scholars noted organizational identity should be characterized by instability, thus the ability of members to adopt the change is not enduring (Gioia et al., 2000). Albert and Whetten (1985), on one hand, mentioned the multiplicity nature of organizational identity. Firms' success in organizational change is related to members' willingness to accept the change and form the transformed organizational identity.

"I really don't know the reality of TIM because I started to work in JOL and I never experienced working at TIM. JOLs are not independent but maybe something similar. Because most of them (JOLs) are not working on the core business of TIM." (Newly hired employee)

On the other hand, Gustafson \& Reger (1995) claimed that identity in an organization is a multilayer construct with core parts and organizational change can, therefore, occur without meaningful change in the core identity. Although these views represent theoretical bases, our empirical case shows that success could be achieved in the first phase of transformation. Ideally, this would happen by making sense of new organizational identity with employees, while reinforcing core company's identity. These two are not mutually excluding. Managers who keep close contact with the core company, manage to overcome the early period of ambiguity faster. Younger members of the organizations, hired had hoc in the JOLs, are willing to be associated with the parent company: this might be because of TIM's reputation which lies in its brand rather than its laboratories. Our explanatory case shows that sensemaking practices should be included in the early phase of transformation. According to Weick et al. (2005), identity formulation represents a sensemaking process enabling employees to build new events on top of past experiences, and to meaningfully interpret and incorporate new information into a frame of explanatory reference. These practices include daily formal and informal collaborations with new colleagues in new institutions, trust building efforts, coordinated events with the core company and laboratories, and mission alignment with new colleagues from the merging laboratory.

\subsection{Second stage: From identity ambiguity to construct an open identity}

Being in a period of identity ambiguity requires organizations to react efficiently in order to overcome this period by deploying certain practices. The evolution of the identity over time and the emergence of new organizational images and values will need to pass through parallel processes of sensemaking. During this period, managers' sensemaking efforts help employees to overcome the ambiguity process and reconstruct the identity, which is needed to ensure a smooth functioning of the working environment and performance of the laboratories.

"JOL is not like a start-up, we are employee of TIM and there is a collaboration between university and the company. We are part of this collaboration which is regulated through a contract "(JOL director/Transferred)

Vs. 
"We are like start-up. If we are not connected to different departments of TIM, then we are not very different from being a start-up." (Transferred employee)

We identified two sets of actions: 1) from vision shift and goal misalignment, to constructing an open identity, and 2) trust building and identity negotiation.

From vision shift and goal misalignment to construct an open identity:

Temporal divergences began to emerge when employees started to determine how the mission is differently perceived by the university representatives in the office. One debatable question for employees was why TIM established joint laboratories. The answer to this question was different from the perspective of different unit's representatives in the labs. It is clear that TIM members recognized and accepted the rationale for university-industry collaboration, and the reality that they were going to be partially independent from the mother company, but also responsible for TIM's core vision.

"I do not know very well the structure of my company (TIM), I am very interested on what I do in terms of technical world. I just need to know the structure of my team, like who is my boss and the boss of my boss, and that's it." (Newly hired employee)

Employees were totally aware of the fact that the existing organizational structure of TIM would influence their actions and interactions on one hand and, on the other hand, they had to produce income together with their new peers as a separate entity. That is supported by the definition of identity ambiguity. However, some practice of the management level of the JOLs led employees to take off from ambiguity phase and reconstruct identity.

"I moved from TIM environment and now I have the possibility to work with students and professor in a totally new environment. This needs a totally new mindset because we have different point of views. That is not easy, but it is possible." (Transferred employees)

Laboratory directors who took a proactive role in making sense of the new organization by giving meaning to new visions and how lab members should achieve those visions, were able to reconstruct a shared identity. A change in the vision requires a change in the organizational identity; hence, shared visionary environment like university-industry collaborative centers requires constructing a shared organizational identity by leaders. The conflict over mission and vision related to identity ambiguity is a twofold problem: a flexible mission should be formed for university members who join the laboratories, on the one side, while TIM employees should start understanding and making sense of university vision and change their company's one, on the other side. Our data showed that these conflicts decrease as interactions increases through events, formal and informal meetings. Making sense of the differences in the visions is considered beneficial in constructing a shared identity.

"I moved from T-lab (the company's research center) to the JOLs. I have to say the organizational perspectives are very different. We as an organization are trying to achieve our goals." (Transferred employee)

This process is an alternating process that should be led by lab directors to simultaneously reinforce the core company's identity and reconstruct the shared identity. Often, our respondents 
called for more recognition from TIM, as they perceived themselves more as a TIM employee rather than a lab one.

Trust building and identity negotiation:

As Gioia et al. (2010, p. 4) indicated, "identity formation is likely to be a complex process subject to multiple influences and infused with ambiguity and one in which organizational identity is not defined solely by founders and leaders but negotiated by both insiders and outsiders." Our empirical data support this in the second phase of identity transformation in the university-industry joint laboratories. Reconstructing a shared identity could be the result of negotiation and sensemaking between stakeholders involved in the organization. In this context, trust between members from university or industry facilitate the process of negotiation for building a shared identity. The process of fostering trust within organizations is a result of effective communication organized and managed by leaders. Therefore, according to our empirical setting, the labs with effective communication techniques speeds up the process of trust formation and enter negotiation and identity construction. Different members from university and industry often define laboratory identity the same way, regardless of the connection to the parent company.

"I see myself not only the lab member. I would like to know also what happens in TIM. To better know the company's status and what they are heading to." (Newly hired employee)

They mutually shape norms and values for the laboratories and define themselves as a part of this organization. The laboratories that lack effective communication, leadership and interactions, on the contrary, experience ambiguity for a longer period. Langley et al. (2012) found that the boundary spanners and the employees negotiate different aspects of sameness and differences between the old and new identities. In our case, leaders facilitated the knowledge sharing processes, thus trust formation, when all the members of the new entity started to define and form an identity, which is newly distinct and central if compared to the previously existing one.

\section{Identity Transformation Process in Open Innovation Initiati- ves}

The main finding of this study is the analytical model for the process of identity transformation when a company opens its business model by establishing laboratories outside the firm boundaries, within the university. In our case, TIM established joint laboratories with major Italian universities within their sites. This happened through a change in the institutional and organizational settings. Figure 1 shows the process of employees' organizational identity transformation.

The identity of corporate employees that move to work in joint laboratories within universities reflects a growing sense of identity ambiguity among the members and how they construct a new shared identity. The figure represents the emergence of identity ambiguity and its increasing tension before and during the opening up period, which are followed by efforts to restore the shared identity. The activities of sensemaking are continuous throughout the process. The dynamics of identity transformation entail three stages: parent company's core identity, identity 


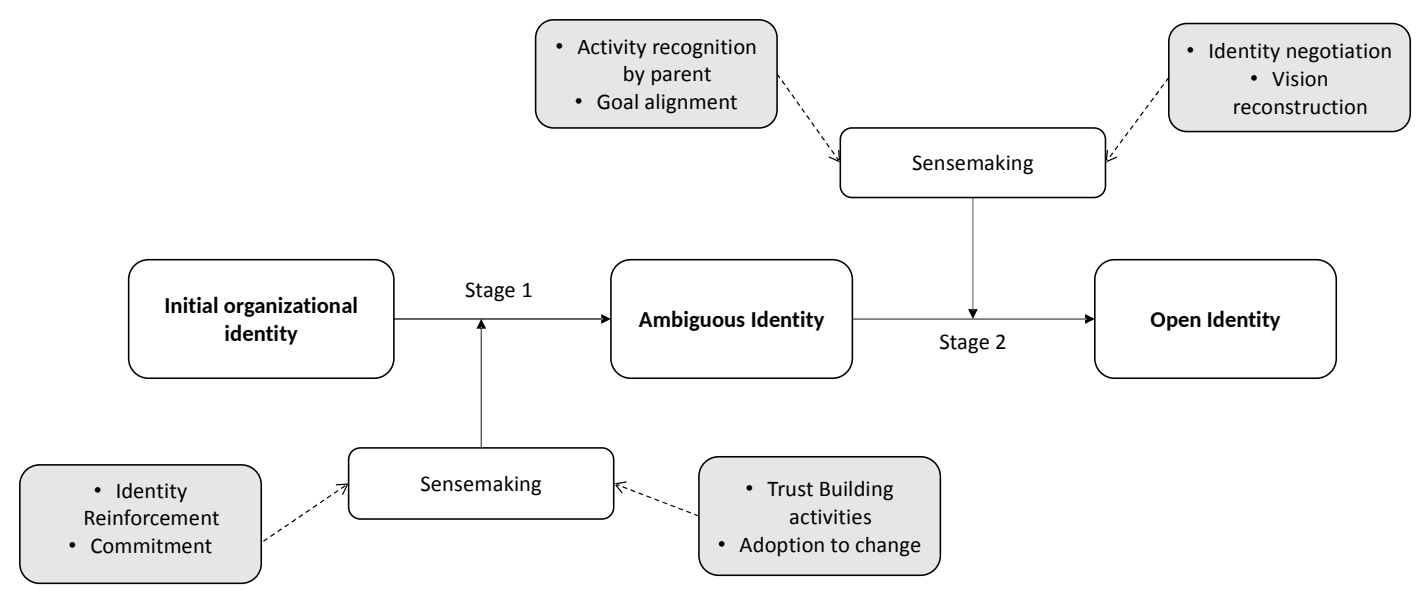

Fig. 1. The process of employees' organizational identity transformation

ambiguity, and restored shared identity. Furthermore, the effectiveness of leaders' sensemaking practices to move away from identity ambiguity phase results crucial.

\section{Conclusions}

Studying the phenomena of organizational identity change during the process of open innovation implementation suggests the followings:

1. The process of open innovation through the mobility of skilled $R \& D$ employees triggers organizational identity ambiguity and change;

2. The phase of organizational identity ambiguity in the process of open innovation can be shortened by the support of the parent company and the deployment of managerial skills;

3. Constructing a shared organizational identity with university members involved in the open innovation process is necessary and possible with leadership efforts.

This study contributes to the open innovation literature and offers implications for research on organizational identity change and transformation. Our findings support earlier research showing the complexity of conducting research in the areas related to processes of organizational identity (Whetten 2006). Although implementing open innovation through the mobility of skilled workers might bring external sources of knowledge, and therefore revenue, the organization and management of these approaches require accurate considerations in balancing identity issues of $R \& D$ professionals with the parent company and/or with the joint activities, as to manage the impacts on innovation and change acceptance (Lifshitz-Assaf, 2018). The results emerging from our case support earlier research on the importance of sensemaking and negotiation in the process of organizational identity, especially in the reconstruction phase (Hamalainen, 2007; Gioia et al. 2010). Based on our analyses, the formation of shared identity or co-existence of multiple identity, could be possible if - and only if - it adds value to the organization. This topic has been discussed admirably in the research related to organizational identity and mergers and acquisition (Bond 
and Seneque, 2012). However, as our case showed, constructing a shared identity rather than coping with co-existence of multiple ones can be more beneficial because of the severe cultural differences. According to the research on organizational identity within an international joint venture (IJV) dual identification with the IJV and the parent company might lead to significant conflicts, especially at the management level, and more stress at the individual level (Li et al., 2002). We observed that younger employees tend to resist more to the organizational identity change. This might be due to the importance that the image and power of the parent company assume for them. Less experienced employees in our case reflect more heterogeneous perspective on their identity. The reason could be that they tried to build a non-collaborative identity, either professional or organizational, in order to achieve collaboration goals. However, Corley (2004) suggested that organization members should consciously consider the possibility that their perception of 'who the organization is' differs from the one of their colleagues, because of perceptual differences regarding the need for change in the organization. Clark et al. (2010) and Gioia and Thomas (1996) confirmed that strategic or transformational change are improbable to be done successfully without relative identity change. This is also confirmed by our study of open innovation phenomena underlying the importance of organizational identity change of mobile employees within the process of transformation.

In sum, our research offers a new perspective in the era of open innovation. Despite the limitations of our study, we shed light on the managerial practices of open innovation settings. Efforts in constructing a shared identity would help firms to avoid identity conflicts, thus benefiting efficiently from open innovation practices. We do not know yet how identity differentiation between laboratories and the parent company ultimately affects organizational and innovation performance. Nonetheless, the recognition and acceptance of its possibility within the organization is an important first step in diminishing negative consequences. The important role of leaders in the sensemaking process is an undeniable factor in overcoming identity ambiguity phase. In addition to our theoretical contributions, we can argue that firms could benefit from understanding the subsequent effects of adapting to open innovation paradigm particularly by taking advantage from the mobility of skilled employees in the generation of joint innovation.

\section{References}

Albert, S., \& Whetten, D. A. (1985). Organizational identity (Vol.7). Research in organizational behavior, 263-295.

Arrow, K. (1962). Economic welfare and the allocation of resources for invention. National Bureau of Economical Research: The Rate and Direction of Inventive Activity: Economic and Social Factors, I, S. 609-626.

Ashforth, B. E., \& Mael, F. (1989). Social identity theory and the organization. Academy of management review, 14(1), 20-39.

Bartels, J., Douwes, R., Jong, M., \& Pruyn, A. (2006). Organizational identification during a merger: Determinants of employees' expected identification with the new organization. British Journal of Management,17(S1), S49-S67. 
Belderbos, R., Carree, M., \& Lokshin, B. (2004). Cooperative R\&D and firm performance. Research policy, 33(10), 1477-1492.

Blau, J. (2007). Philips Tears Down Eindhoven R\&D Fence. Research Technology Management, 50(6), 9 .

Bogers, M, A-K Zobel, A Afuah, E Almirall, S Brunswicker, L Dahlander, L Frederiksen, A Gawer, M Gruber and S Haefliger (2017). The open innovation research landscape: Established perspectives and emerging themes across different levels of analysis. Industry and Innovation, $24,8-40$.

Bond, C., \& Seneque, M. (2012). Exploring organizational identity in the context of transformational change: A South African case study. Journal of Change Management, 12(1), 13-30.

Chesbrough, H. (2006). Open innovation: a new paradigm for understanding industrial innovation. Open innovation: Researching a new paradigm, 1-12.

Chesbrough, H. Bogers, M.(2014). Explicating open innovation: Clarifying an emerging paradigm for understanding innovation. H. Chesbrough, W. Vanhaverbeke \& J. West (Eds.), New Frontiers in open Innovation, 3-28.

Chesbrough, H. W. (2006). The era of open innovation. Managing innovation and change, 127(3), $34-41$.

Clark, S. M., Gioia, D. A., Ketchen, D. J., \& Thomas, J. B. (2010). Transitional identity as a facilitator of organizational identity change during a merger. Administrative Science Quarterly, 55(3), 397-438.

Corley, K. G. (2004). Defined by our strategy or our culture? Hierarchical differences in perceptions of organizational identity and change. Human relations, 57(9), 1145-1177.

Corley, K. G., \& Gioia, D. A. (2004). Identity ambiguity and change in the wake of a corporate spin-off. Administrative Science Quarterly, 49(2), 173-208.

Corley, K. G., Harquail, C. V., Pratt, M. G., Glynn, M. A., Fiol, C. M., \& Hatch, M. J. (2006). Guiding organizational identity through aged adolescence. Journal of Management Inquiry, 15(2), 85-99.

De Fuentes, C., \& Dutrénit, G. (2012). Best channels of academia-industry interaction for long-term benefit. Research Policy, 41(9), 1666-1682.

De Marco, C.E., 2017. The Challenges of Implementing Open Innovation. A Systematic Literature Review. Scuola. Superiore Sant'Anna, Pisa.

De Marco, C. E., Martelli, I., \& Di Minin, A. (2020). European SMEs' engagement in open innovation When the important thing is to win and not just to participate, what should innovation policy do?. Technological Forecasting and Social Change, 152, 119843.

Denzin, N. K., \& Lincoln, Y. S. (2000). The discipline and practice of qualitative research. Handbook of qualitative research, 2, 1-28.

Dodgson, M., Gann, D., \& Salter, A. (2006). The role of technology in the shift towards open innovation: the case of Procter \& Gamble. RÉD Management,36(3), 333-346. 
Dutton, J. E., \& Dukerich, J. M. (1991). Keeping an eye on the mirror: Image and identity in organizational adaptation. Academy of management journal,34(3), 517-554.

Feller, I. (2005). A historical perspective on government-university partnerships to enhance entrepreneurship and economic development. Economic development through entrepreneurship: Government, university and business linkages, 6-28.

Fiol, C. M. (1991). Managing culture as a competitive resource: An identity-based view of sustainable competitive advantage. Journal of management,17(1), 191-211.

Fiol, C. M. (2002). Capitalizing on paradox: The role of language in transforming organizational identities. Organization Science, 13(6), 653-666.

Florida, R. (2000). Competing in the Age of Talent. The Software Industry Center at Carnegie Mellon University.

Gill, M. J. (2014). The possibilities of phenomenology for organizational research. Organizational Research Methods, 17(2), 118-137

Gilson, R. J. (1999). The legal infrastructure of high technology industrial districts: Silicon Valley, Route 128, and covenants not to compete. New York University Law Review, 74(3), 575-629.

Gioia, D. A. (1998). From individual to organizational identity. Identity in organizations: Building theory through conversations, 11, 17-31.

Gioia, D. A., \& Thomas, J. B. (1996). Identity, image, and issue interpretation: Sensemaking during strategic change in academia. Administrative science quarterly, 370-403.

Gioia, D. A., Patvardhan, S. D., Hamilton, A. L., \& Corley, K. G. (2013). Organizational identity formation and change. The Academy of Management Annals, 7(1), 123-193.

Gioia, D. A., Price, K. N., Hamilton, A. L., \& Thomas, J. B. (2010). Forging an identity: An insider-outsider study of processes involved in the formation of organizational identity. Administrative Science Quarterly, 55(1), 1-46.

Gustafson, L. T., \& Reger, R. K. (1995, August). USING ORGANIZATIONAL IDENTITY TO ACHIEVE STABILITY AND CHANGE IN HIGH VELOCITY ENVIRONMENTS. In Academy of Management Proceedings (Vol. 1995, No. 1, pp. 464-468). Academy of Management.

Hämäläinen, V. (2007). Struggle over" who we are": a discursive perspective on organizational identity change. Helsinki University of Technology.

Harwing, R. (2004). Open Innovation. Philips Research Password, 19, 1-13.

Hatch, M. J., \& Schultz, M. (2002). The dynamics of organizational identity. Human relations, 55(8), 989-1018.

Herstad, S. J., Sandven, T., \& Ebersberger, B. (2015). Recruitment, knowledge integration and modes of innovation. Research Policy, 44(1), 138-153.

Husted, K., \& Michailova, S. (2010). Dual allegiance and knowledge sharing in inter-firm R\&D collaborations. Organizational Dynamics, 39(1), 37. 
Klevorick, A. K., Levin, R. C., Nelson, R. R., \& Winter, S. G. (1995). On the sources and significance of interindustry differences in technological opportunities. Research policy, 24(2), $85-205$.

Kvale, S. (1996). Interviews. An introduction to qualitative research writing. Sage.

Langley, A., Smallman, C., Tsoukas, H., \& Van de Ven, A. H. (2013). Process studies of change in organization and management: unveiling temporality, activity, and flow. Academy of Management Journal, 56(1), 1-13.

Li, J., Xin, K., \& Pillutla, M. (2002). Multi-cultural leadership teams and organizational identification in international joint ventures. International Journal of Human Resource Management, 13(2), 320-337.

Lifshitz-Assaf, H. (2018). Dismantling knowledge boundaries at NASA: The critical role of professional identity in open innovation. Administrative science quarterly, 63(4), 746-782.

Mahdad, M., Bogers, M., Piccaluga, A., \& Di Minin, A. (2018). Exploring the Organization of University-Industry Joint Laboratories: A Leadership Perspective'. Kristian J. Sund Robert J. Galavan Stefano Brusoni (ed.) Cognition and Innovation, 3, 141-173.

Mahdad, M., De Marco, C. E., Piccaluga, A., \& Di Minin, A. (2020). Harnessing adaptive capacity to close the pandora's box of open innovation. Industry and Innovation, 27(3), 264284

Melewar, T. C., \& Harrold, J. (2000). The role of corporate identity in merger and acquisition activity. Journal of General Management, 26(2), 17-31.

Navis, C., \& Glynn, M. A. (2010). How new market categories emerge: Temporal dynamics of legitimacy, identity, and entrepreneurship in satellite radio, 1990-2005. Administrative Science Quarterly, 55(3), 439-471.

Nelson, R. R. (2004). The market economy, and the scientific commons. Research policy, 33(3), 455-471.

Perkmann, M., Tartari, V., McKelvey, M., Autio, E., Broström, A., D’Este, P., ... \& Krabel, S. (2013). Academic engagement and commercialisation: A review of the literature on university-industry relations. Research policy, 42(2), 423-442.

Perkmann, M., \& Walsh, K. (2007). University-industry relationships and open innovation: Towards a research agenda. International Journal of Management Reviews, 9(4), 259-280.

Petroni, G., Venturini, K., \& Verbano, C. (2012). Open innovation and new issues in R\&D organization and personnel management. The International Journal of Human Resource Management, 23(1), 147-173.

Pólos, L., Hannan, M. T., \& Carroll, G. R. (2002). Foundations of a theory of social forms. Industrial and Corporate Change, 11(1), 85-115.

Randhawa, K, R Wilden and J Hohberger (2016). A bibliometric review of open innovation: Setting a research agenda. Journal of Product Innovation Management, 33, 750-772. 
Ravasi, D., \& Phillips, N. (2011). Strategies of alignment organizational identity management and strategic change at Bang \& Olufsen. Strategic Organization, 9(2), 103-135.

Reade, C. (2001). Antecedents of organizational identification in multinational corporations: Fostering psychological attachment to the local subsidiary and the global organization. International Journal of Human Resource Management, 12(8), 1269-1291.

Reissner, S. 2019. 'We are this hybrid': Members' search for organizational identity in an institutionalized public-private partnership'. Public Administration, 97 (1), 48-63.

Rohrbeck, R., Hölzle, K., \& Gemünden, H. G. (2009). Opening up for competitive advantage-How Deutsche Telekom creates an open innovation ecosystem. R\&d Management, 39(4), 420-430.

Salampasis, D., \& Mention, A. L. (2017). Open Innovation: Unveiling the Power of the Human Element. World Scientific Publishing Co. Pte. Ltd.

Salter, A., Wal, A. L., Criscuolo, P., \& Alexy, O. (2015). Open for Ideation: Individual-Level Openness and Idea Generation in R\&D. Journal of Product Innovation Management, 32(4), 488-504.

Saxenian, A. (1994). Regional networks: industrial adaptation in Silicon Valley and route 128.

Scott, S. G., \& Lane, V. R. (2000). A stakeholder approach to organizational identity. Academy of Management review, 25(1), 43-62.

Smith, J. A. (1996). Beyond the divide between cognition and discourse: Using interpretative phenomenological analysis in health psychology. Psychology and health, 11(2), 261-271.

Smith, J. A. (2004). Reflecting on the development of interpretative phenomenological analysis and its contribution to qualitative research in psychology. Qualitative research in psychology, 1(1), 39-54.

Smith, J. A., Flowers, P., \& Larkin, M. (2009). Interpretative Phenomenological Analysis: Theory. Method and Research London: Sage.

Sorensen, A. (2008). Media Review: NVivo 7. Journal of Mixed Methods Research, 2(1), 106108.

Tripsas, M. (2009). Technology, identity, and inertia through the lens of "The Digital Photography Company". Organization science, 20(2), 441-460.

Todtling, F., \& Trippl, M. (2007). Knowledge links in high-technology industries: Markets, Networks or Milieu? The case of the Vienna biotechnology cluster. International Journal of Entrepreneurship and Innovation Management, 7(2-5), 345-365.

Ullrich, J., Wieseke, J., \& Dick, R. V. (2005). Continuity and change in mergers and acquisitions: A social identity case study of a German industrial merger. Journal of Management Studies, 42(8), 1549-1569.

Vaara, E. (2003). Post-acquisition integration as sensemaking: glimpses of ambiguity, confusion, hypocrisy, and politicization. Journal of management studies, 40(4), 859-894. 
Vaara, E., Tienari, J., \& Säntti, R. (2003). The international match: Metaphors as vehicles of social identity-building in cross-border mergers. Human Relations, 56(4), 419-451.

van de Vrande, V., Vanhaverbeke, W., \& Gassmann, O. (2010). Broadening the scope of open innovation: past research, current state and future directions. International Journal of Technology Management, 52(3/4), 221-235.

Van Dick, R., Grojean, M. W., Christ, O., \& Wieseke, J. (2006). Identity and the extra mile: Relationships between organizational identification and organizational citizenship behaviour. British Journal of Management, 17(4), 283-301.

Van Knippenberg, D., \& Van Leeuwen, E. (2001). Organizational identity after a merger: Sense of continuity as the key to post-merger identification. In Social identity processes in organizational contexts (pp. 249-264). Psychology Press.

Vieru, D., \& Rivard, S. (2012, March). Shifting sand: Organizational identity, partnership and IT outsourcing. In International Workshop on Global Sourcing of Information Technology and Business Processes (pp. 93-104). Springer Berlin Heidelberg.

Webb, J. (2017). Keeping alive inter-organisational innovation through identity work and play. International Journal of Innovation Management, 21(05), 1740009.

Weick, K. E., Sutcliffe, K. M., \& Obstfeld, D. (2005). Organizing and the process of sensemaking. Organization science, 16(4), 409-421.

West, J., \& Bogers, M. (2014). Leveraging external sources of innovation: a review of research on open innovation. Journal of Product Innovation Management, 31(4), 814-831.

Whetten, D. A. (2006). Albert and Whetten revisited: Strengthening the concept of organizational identity. Journal of Management Inquiry, 15(3), 219-234.

Willig, C. (2001). Qualitative research in psychology: A practical guide to theory and method. Buckingham: OUP.

Yusuf, S. (2008). Intermediating knowledge exchange between universities and businesses. Research Policy, 37(8), 1167-1174. 


\section{Biographies}

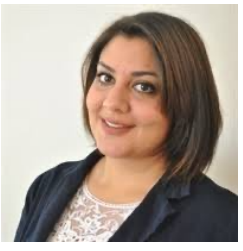

Maral Mahdad. Maral Mahdad is a senior researcher and lecturer of innovation and entrepreneurship at Wageningen University and Research (WUR) at the Department of Business Management and Organization (BMO). She formerly was postdoctoral fellow of Innovation Management at the department Food and Resource Economics of University of Copenhagen. She has a Master's in Innovation Management from the Scuola Superiore Sant'Anna and the University of Trento. She obtained her Ph.D. in Management at Scuola Superiore Sant'Anna, in Italy. Her research activities focus on innovation management, open innovation, universityindustry collaborations and ecosystems. She has several peer-reviewed articles on these topics in innovation management journals.

CRediT Statement: Conceptualization; Methodology; Formal analysis; Investigation; Data Curation; Writing Original Draft.

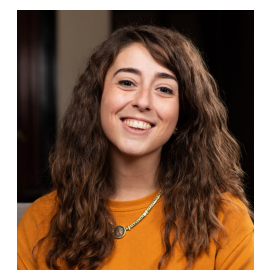

Chiara E. De Marco. Chiara Eleonora De Marco was born in Cosenza, Italy, in 1985. She received a degree in international law at LUMSA University in 2010 (Rome, Italy), and two Master's Degrees in diplomatic studies (2011) and international relations and international protection of human rights (2013), from the Società Italiana per l'Organizzazione Internazionale (SIOI - Rome, Italy). In 2017 she got her Ph.D. degree in innovation management from the Scuola Superiore Sant'Anna (Pisa, Italy). She was Postdoctoral Scholar at Scuola Superiore Sant'Anna and Haas School of Business of the University of California, Berkeley (USA). Working on Corporate Capability Building Programs for Digital Transformation, she conducted research on both small and large corporations, led projects on Open Innovation, digital business model and strategy, innovation policy, technology and knowledge transfer. She publishes her work on international scientific journals and practitioner-oriented reviews. Dr. De Marco is currently Open Innovation Consultant in the Strategic Innovation Services Team of CiaoTech/PNO Group. She is member of the World Open Innovation Conference Organizing Committee and in charge of the management of Industry Sessions and Workshops.

CRediT Statement: Conceptualization; Writing - Review $\&$ Editing.

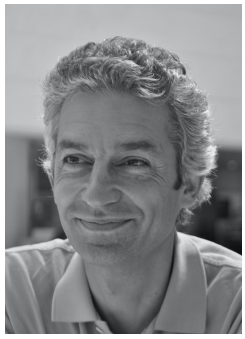

Andrea Piccaluga. Andrea Piccaluga was born in Genova (Italy), in 1964. He received a PhD from Scuola Superiore Sant'Anna and a Master in Technology and Innovation Management from SPRU (University of Sussex, Brighton). He became assistant professor at Scuola Superiore Sant'Anna, then associate professor at Università del Salento and then full professor at Scuola Superiore Sant'Anna, where he is the Director of the Institute of Management. He is vice-president of Netval, the Italian association of University Technology Transfer Offices, after being president from 2014 to 2019. He has published books and papers in R\&D management, Open Innovation, Regional Innovation Policies, high-tech entrepreneurship and Technology Transfer. He is Associate editor of the R\&D Management Journal.

CRediT Statement: Supervision; Funding Acquisition.

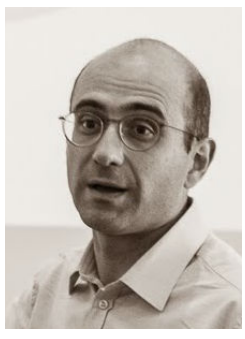

Alberto Di Minin. Alberto Di Minin got a Ph.D. from the University of Berkeley in California. Now he is Full Professor of Management at the Sant'Anna School of Pisa. His research and teaching deals with the appropriation of innovation. In particular he focuses on open innovation and business model innovation. He also works science and technology policy, technology transfer, intellectual property and R\&D management. He is director of the new MASTER MIND - Management of Innovation and Design at the Sant'Anna School of Pisa and is Co-Director of the Confucius Institute of Pisa and of the Galilei Institute at Chongqing University. Collaborate with Nòva del Sole24Ore. www.diminin.it .

CRediT Statement: Supervision

ISSN 2183-0606

http://www.open-jim.org

http://creativecommons.org/licenses/by/3.0 